\title{
Complete basic childhood vaccination and associated factors among children aged 12-23 months in East Africa: a multilevel analysis of recent demographic and health surveys
}

Getayeneh Antehunegn Tesema* (1), Zemenu Tadesse Tessema, Koku Sisay Tamirat and Achamyeleh Birhanu Teshale

\begin{abstract}
Background: Complete childhood vaccination remains poor in Sub-Saharan Africa, despite major improvement in childhood vaccination coverage worldwide. Globally, an estimated 2.5 million children die annually from vaccinepreventable diseases. While studies are being conducted in different East African countries, there is limited evidence of complete basic childhood vaccinations and associated factors in East Africa among children aged 12-23 months. Therefore, this study aimed to investigate complete basic childhood vaccinations and associated factors among children aged 12-23 months in East Africa.

Methods: Based on the Demographic and Health Surveys (DHSs) of 12 East African countries (Burundi, Ethiopia, Comoros, Uganda, Rwanda, Tanzania, Mozambique, Madagascar, Zimbabwe, Kenya, Zambia, and Malawi), secondary data analysis was performed. The study included a total weighted sample of 18,811 children aged 12-23 months. The basic childhood vaccination coverage was presented using a bar graph. Multilevel binary logistic regression analysis was fitted for identifying significantly associated factors because the DHS has a hierarchical nature. The Intra-class Correlation Coefficient (ICC), Median Odds Ratio (MOR), Proportional Change in Variance (PCV), and deviance (-2LLR) were used for checking model fitness, and for model comparison. Variable with $p$-value $\leq 0.2$ in the bi-variable multilevel analysis were considered for the multivariable analysis. In the multivariable multilevel analysis, the Adjusted Odds Ratio (AOR) with 95\% Confidence Interval (Cl) were reported to declare the significance and strength of association with full vaccination.

* Correspondence: getayenehantehunegn@gmail.com

Department of Epidemiology and Biostatistics, Institute of Public Health, College of

Medicine and Health Sciences, University of Gondar, Gondar, Ethiopia

(c) The Author(s). 2020 Open Access This article is licensed under a Creative Commons Attribution 4.0 International License, which permits use, sharing, adaptation, distribution and reproduction in any medium or format, as long as you give appropriate credit to the original author(s) and the source, provide a link to the Creative Commons licence, and indicate if changes were made. The images or other third party material in this article are included in the article's Creative Commons licence, unless indicated otherwise in a credit line to the material. If material is not included in the article's Creative Commons licence and your intended use is not permitted by statutory regulation or exceeds the permitted use, you will need to obtain permission directly from the copyright holder. To view a copy of this licence, visit http://creativecommons.org/licenses/by/4.0/ The Creative Commons Public Domain Dedication waiver (http://creativecommons.org/publicdomain/zero/1.0/) applies to the data made available in this article, unless otherwise stated in a credit line to the data. 
(Continued from previous page)

Results: Complete basic childhood vaccination in East Africa was 69.21\% (95\% Cl, 69.20, 69.21\%). In the multivariable multilevel analysis; Mothers aged 25-34 years ( $\mathrm{AOR}=1.21,95 \% \mathrm{Cl}: 1.10,1.32)$, mothers aged 35 years and above (AOR $=$ $1.50,95 \% \mathrm{Cl}: 1.31,1.71)$, maternal primary education $(A O R=1.26,95 \% \mathrm{Cl}: 1.15,1.38)$, maternal secondary education and above $(A O R=1.54,95 \% \mathrm{Cl}: 1.36,1.75)$, husband primary education ( $\mathrm{AOR}=1.25,95 \% \mathrm{Cl}: 1.13,1.39)$, husband secondary education and above $(A O R=1.24,95 \% \mathrm{Cl}: 1.11,1.40)$, media exposure (AOR $=1.23,95 \% \mathrm{Cl}: 1.13,1.33)$, birth interval of 2448 months ( $A O R=1.28,95 \% \mathrm{Cl}: 1.15,1.42)$, birth interval greater than 48 months ( $\mathrm{AOR}=1.35,95 \% \mathrm{Cl}$ : 1.21, 1.50), having 13 ANC visit (AOR $=3.24,95 \% \mathrm{Cl}: 2.78,3.77)$, four and above $A N C$ visit (AOR =3.68, 95\% Cl: 3.17, 4.28), PNC visit (AOR $=1.34$, $95 \% \mathrm{Cl}: 1.23,1.47)$, health facility delivery $(A O R=1.48,95 \% \mathrm{Cl}: 1.35,1.62)$, large size at birth $1.09(\mathrm{AOR}=1.09,95 \% \mathrm{Cl}: 1.01$, 1.19), being 4-6 births ( $A O R=0.83,95 \% \mathrm{Cl}: 0.75,0.91)$, being above the sixth birth ( $\mathrm{OOR}=0.60,95 \% \mathrm{Cl}: 0.52,0.70)$, middle wealth index $(A O R=1.16,95 \% \mathrm{Cl}: 1.06,1.28)$, rich wealth index $(A O R=1.20,95 \% \mathrm{Cl}: 1.09,1.33)$, community poverty $(A O R=1.21,95 \% \mathrm{Cl}: 1.11,1.32)$ and country were significantly associated with complete childhood vaccination.

Conclusions: In East Africa, full basic childhood vaccine coverage remains a major public health concern with substantial differences across countries. Complete basic childhood vaccination was significantly associated with maternal age, maternal education, husband education, media exposure, preceding birth interval, number of ANC visits, PNC visits, place of delivery, child-size at birth, parity, wealth index, country, and community poverty. Public health interventions should therefore target children born to uneducated mothers and fathers, poor families, and those who have not used maternal health services to enhance full childhood vaccination to reduce the incidence of child mortality from vaccine-preventable diseases.

Keywords: Complete basic vaccination, Multilevel analysis, East Africa

\section{Background}

An estimated 5.3 million children under the age of five have died worldwide, the highest in Africa [1]. Children in SubSaharan Africa (SSA), particularly East Africa, are more than 15 times more likely than children in high-income countries to die before the age of five $[2,3]$. More than half of these deaths are preventable or can be handled with simple, affordable interventions, including immunization, proper nutrition, clean water, and food $[4,5]$.

Vaccinations against childhood infectious diseases minimize the mortality risk of two-thirds of children under five [6]. Pneumonia and diarrhea, the leading causes of under-five deaths, can be avoided by vaccination [7-9]. Vaccination is the most cost-effective public health strategy for the prevention and eradication of infectious childhood diseases such as measles, pertussis, diphtheria, tetanus, tuberculosis, meningitis, and tuberculosis in children [10-13]. Basic childhood vaccines (BCG, pentavalent, polio, and measles) prevents an estimated 2-3 million deaths of under-five children annually [13-15].

The World Health Organization (WHO) initiated an Extended Program on Immunization (EPI) to establish and extend immunization services worldwide in 1974 to minimize child mortality [16]. Following the launch of the EPI program, the incidence of under-five deaths dropped dramatically from 12.6 million in 1990 to 5.3 million in 2018 [17, 18]. The region with the world's highest infant and under-five mortality remains SSA, especially East Africa [19], and this could be closely linked with the take-up of vaccinations [20].
In 2018, 13.5 million children were not vaccinated worldwide [21]. Although considerable progress has been made internationally on vaccination coverage, there is a substantial difference in the coverage of vaccines among countries [22]. For European nations, the performance of DPT1 and DPT3 is 97 and 94\% respectively, while for Africa, it is 84 and $76 \%$ respectively [23]. As for the measles vaccine, it is $95 \%$ in developed countries and $74 \%$ in Africa [24].

Prior studies on basic childhood vaccination revealed that residence [25-27], maternal occupation status [28, $29]$, sex of household head [30, 31], wealth status [27, 32], maternal education status [33], husband education status [34], wealth status [27, 35], number of Antenatal Care (ANC) visit [36], place of delivery [27], Postnatal Care (PNC) visit [37], media exposure [35], maternal marital status [27], maternal age [38], parity [39, 40], child-size at birth, mode of delivery [41], twin birth and preceding birth interval were significantly associated factors of complete basic childhood vaccination.

Though there are studies conducted on the prevalence and associated factors of complete basic childhood vaccination in different countries in East Africa [42-45]; as to our search of the literature, there is no study conducted on the complete basic childhood vaccination and associated factors among children aged 12-23 months in East Africa based on the pooled Demographic and Health Surveys (DHSs) data. Investigating complete basic childhood vaccination and its associated factors in East Africa is crucial to assess cross-national disparity in vaccination coverage. Besides, the study had the 
adequate statistical power to detect the true effects of variables hence the study is based on the pooled DHS data in East Africa. Therefore, this study aimed to investigate the complete basic childhood vaccinations and associated factors among children aged 12-23 months in East Africa using DHS data of 12 countries.

\section{Methods}

\section{Data source and sampling procedure}

This study was based on 12 East African countries' DHS data. The secondary data analysis was based on the most recent DHS datasets conducted in Burundi, Ethiopia, Comoros, Uganda, Rwanda, Mozambique, Madagascar, Zimbabwe, Kenya, Zambia, Malawi, and Tanzania. These datasets were appended together to investigate complete basic childhood vaccinations and associated factors among children aged 12-23 months in East Africa. The DHSs were a nationally representative survey that collects data on basic health indicators like mortality, morbidity, family planning service utilization, fertility, maternal and child health services (vaccination). The data were derived from the measure DHS program (https://www.dhsprogram.com/Data). Each country's survey consists of different datasets including men, women, children, birth, and household datasets. For this study, we used the Kids record dataset (KR file). The DHS used two stages of stratified sampling technique to select the study participants. In the first stage, Enumeration Areas (EAs) were randomly selected while in the second stage households were selected. The data were derived from the measure DHS program. We pooled the DHS survey data of the 12 East African countries, and a total weighted sample of 18,811 children aged 12-23 months was included in the study.

\section{Variables of the study \\ Outcome variable}

The dependent variable was the complete basic childhood vaccination status of children aged 12-23 months. As WHO recommended, basic childhood vaccines consists of polio, pentavalent (diphtheria, tetanus, pertussis, haemophiles influenza, and hepatitis $B$ vaccine), measles, and Bacillus Calmette Guerin (BCG) that can prevent common childhood infections. Complete basic childhood vaccination achieved when the child received one dose of BCG vaccine, three doses of pentavalent vaccines, three doses of polio vaccines, and one dose of measles vaccines before the age of 12 months, and categorized as "yes". While those who failed to take the recommended doses of vaccine were categorized as "no". The information about child vaccination was derived from the mother's verbal records and the childhood immunization card data extraction. A random variable Yi represents the $i^{\text {th }}$ child's response variable with two possible values coded as 1 and 0 . As a result, the ith child Yi response variable was measured as a dichotomous variable with possible values of "Yi $=1$ " if the ith child was completely vaccinated and " $\mathrm{Yi}=0$ " if the child was not completely vaccinated.

\section{Independent variables}

In this study, we considered independent variables at two levels. At level one, the individual-level variables such as maternal age, sex of the child, maternal education, paternal education, media exposure, wealth index, maternal occupation, marital status, sex of head of the household, ANC visit, parity, preceding birth interval, place of delivery, and child-size at birth were included. At level two, community-level variables such as community media exposure, community women education, community poverty, country, and place of residence were considered. In DHS, except residence and country, all the variables are collected at the individual level. Therefore, we generate community-level variables such as community education and community media exposure) by aggregating women's education and media exposure at the cluster level. It was categorized as low or high using the national median value since these were not normally distributed.

\section{Data management and analysis}

The variables were extracted using the KR file and data cleaning, recoding, and analysis were done using STATA version 14 statistical software. After appending the extracted data from the 12 East African countries, the data were weighted using sampling weight (v005), primary sampling unit (v023), and strata (v021) to draw valid inferences. The proportion of basic childhood vaccination coverage was presented using a bar graph. The DHS data had a hierarchical structure, and this violates the independence of observations and equal variance assumption of the traditional logistic regression model. Hence children and women were nested within a cluster, they may share similar characteristics within the cluster. This implies that there is a need to consider the between cluster variability by using advanced models. Therefore, multilevel binary logistic regression analysis was employed to identify significantly associated factors of complete childhood vaccination. Likelihood Ratio test (LR), Intra-cluster Correlation Coefficient (ICC), Median Odds Ratio (MOR), and Proportional Change in Variance (PCV) were computed to measure the variation between clusters. Model comparison was made based on deviance (-2LLR) since the models were nested. The ICC quantifies the degree of heterogeneity of complete basic childhood vaccination between clusters (the proportion of the total observed difference in complete 
basic childhood vaccination attributable to cluster variations) [46].

$$
\mathrm{ICC}=\sigma^{2} /\left(\sigma^{2}+\pi^{2} / 3\right) .
$$

MOR was used to quantify the variation or heterogeneity in complete basic childhood vaccination between clusters. It is defined as the median value of the odds ratio between the cluster high odds of complete basic childhood vaccination and cluster at lower odds of complete basic childhood vaccination when randomly picking out two clusters /EAs [47].

$$
\begin{aligned}
\mathrm{MOR} & =\exp \cdot(\sqrt{2 * \partial 2 * 0.6745}) \sim \mathrm{MOR} \\
& =\exp .(0.95 * \partial) .
\end{aligned}
$$

$\partial^{2}$ indicates that cluster variance.

PCV measures the total variation of complete basic childhood vaccination attributed to individual-level and community-level factors in the final model compared to the null model.

$$
\mathrm{PCV}=\frac{\text { var.(null model })- \text { var.full model }))}{\operatorname{Var}(\text { null model })}
$$

Four models were constructed for the multilevel logistic regression analysis. The first model (a model without covariates) was the null model, which was done to determine the extent of cluster variation on complete basic childhood vaccinations. The second model (a multilevel model with level-1 independent variables) was adjusted with individual-level variables; the third model (a multilevel model with level-2 variables) was adjusted for community-level variables while the fourth model was fitted with both individual and community level variables simultaneously. Finally, the fourth model was the bestfitted model since it had the lowest deviance value.

Variables with $p$-value $\leq 0.2$ in the bi-variable analysis for both individual and community-level factors were fitted in the multivariable model. Variables with Adjusted Odds Ratio (AOR) with a 95\% Confidence Interval (CI), and $p$-value $<0.05$ in the multivariable model were reported to declare significantly associated factors of complete basic childhood vaccination. Multi-collinearity was checked using the Variance Inflation Factor (VIF) by doing pseudo-linear regression analysis, which indicates that there was no multicollinearity because all variables have VIF $<5$ and tolerance greater than 0.1 .

\section{Ethics consideration}

Since the study was a secondary data analysis of publicly available survey data from the MEASURE DHS program, ethical approval, and participant consent were not necessary for this particular study. We requested DHS Program, and permission was granted to download and use the data for this study from http://www.dhsprogram. com. There are no names of individuals or household addresses in the data files.

\section{Result}

Socio-demographic and economic characteristics of the study population

A total of 18,811 children aged $12-23$ months were included, of these 9410 (50.1\%) were males. The median age of children was $18(\mathrm{IQR} \pm 5)$ months. Of the total, 3673 (19.5\%) of the children were from Kenya and 618 (3.3\%) were from Comoros. More than three-fourth (76\%) of the children were rural residents. The majority (46.3\%) of the children were born to mothers aged 2534 years, and $24.9 \%$ were from mothers who attained secondary education or higher. About 8639 (45.9\%) of the children were born to mothers from poor households. Two-third (68.3\%) of the children were from the community with low media exposure and $41.2 \%$ were from the community with high poverty (Table 1 ).

\section{Child and maternal-related characteristics}

Of the total of 18,811 children, 13,792 (73.3\%) were born at the health facility, and $1172(6.2 \%)$ were delivered through cesarean section. About 10,592 (56.3\%) of the children were born to mothers who had four and above ANC visits, and 5634 (30\%) were from mothers who had PNC checkups (Table 2).

\section{Coverage of basic childhood vaccination}

The overall complete basic childhood vaccination among children aged 12-23 months in East Africa was 69.21\% (95\% CI: 69.20, 69.21\%) ranged from 39.5\% in Ethiopia to $85 \%$ in Burundi. In East Africa, the vaccination status of children has differed greatly across countries. The proportion of partially vaccinated children in Zimbabwe ranged from 13.4 to $56.1 \%$ in Rwanda, while the proportion of non-vaccinated children ranged from $0.4 \%$ in Burundi to $16 \%$ in Ethiopia (Fig. 1). The highest vaccinespecific coverage for BCG was in Rwanda (99.1\%), measles was in Burundi (93.2\%), polio 3 was in Rwanda (97.1\%), and pentavalent 3 was in Rwanda (98\%) while the lowest vaccine-specific coverage for BCG was in Ethiopia (70.5\%), measles was in Rwanda (43.6\%), polio 3 was in Ethiopia (57.7\%) and pentavalent 3 was in Ethiopia (54.4\%) (Fig. 2 and Fig. 3).

\section{Associated factors of complete basic childhood vaccination}

The ICC in the null model was 0.42 (95\% CI: 0.33, 0.55), indicating that the variations between clusters / EAs were responsible for around $42 \%$ of the overall variability of complete childhood immunization. Besides, the MOR was 1.45 (95\% CI: 1.38, 1.51), meaning that if we 
Table 1 Socio-demographic and economic characteristics of the study population

\begin{tabular}{|c|c|c|}
\hline Variable & Frequency & Percentage (\%) \\
\hline \multicolumn{3}{|l|}{ Country } \\
\hline Burundi & 1323 & 7.0 \\
\hline Ethiopia & 1945 & 10.3 \\
\hline Kenya & 3673 & 19.5 \\
\hline Comoros & 618 & 3.3 \\
\hline Madagascar & 1139 & 6.1 \\
\hline Malawi & 1066 & 5.7 \\
\hline Mozambique & 2280 & 12.1 \\
\hline Rwanda & 762 & 4.1 \\
\hline Tanzania & 2086 & 11.1 \\
\hline Uganda & 916 & 4.9 \\
\hline Zambia & 1846 & 9.8 \\
\hline Zimbabwe & 1156 & 6.1 \\
\hline \multicolumn{3}{|l|}{ Residence } \\
\hline Rural & 14,293 & 76.0 \\
\hline Urban & 4518 & 24.0 \\
\hline \multicolumn{3}{|l|}{ Sex of child } \\
\hline Male & 9410 & 50.1 \\
\hline Female & 9401 & 49.9 \\
\hline \multicolumn{3}{|l|}{ Maternal age } \\
\hline $15-24$ & 6473 & 34.4 \\
\hline $25-34$ & 8716 & 46.3 \\
\hline$\geq 35$ & 3622 & 19.3 \\
\hline \multicolumn{3}{|l|}{ Maternal education } \\
\hline No & 4434 & 23.6 \\
\hline Primary & 9687 & 51.5 \\
\hline Secondary and above & 4690 & 24.9 \\
\hline \multicolumn{3}{|l|}{ Husband education } \\
\hline No & 3025 & 16.1 \\
\hline Primary & 7437 & 39.5 \\
\hline Secondary and above & 8349 & 44.4 \\
\hline \multicolumn{3}{|l|}{ Household wealth status } \\
\hline Poor & 8639 & 45.9 \\
\hline Middle & 3680 & 19.6 \\
\hline Rich & 6492 & 34.5 \\
\hline \multicolumn{3}{|l|}{ Marital status } \\
\hline Single & 1046 & 5.6 \\
\hline Married & 16,224 & 86.2 \\
\hline Widowed/divorced/separated & 1541 & 8.2 \\
\hline \multicolumn{3}{|l|}{ Sex of household head } \\
\hline Male & 14,492 & 77.0 \\
\hline Female & 4319 & 23.0 \\
\hline \multicolumn{3}{|l|}{ Media exposure } \\
\hline No & 6340 & 33.7 \\
\hline
\end{tabular}


Table 1 Socio-demographic and economic characteristics of the study population (Continued)

\begin{tabular}{lll}
\hline Variable & Frequency & Percentage (\%) \\
\hline Yes & 12,471 & 66.3 \\
Community poverty & & 58.8 \\
Low & 11,064 & 41.2 \\
High & 7747 & 77.4 \\
Community women education & & 22.6 \\
Low & 14,554 & \\
High & 4257 & 68.3 \\
Community media exposure & & 31.7 \\
Low & 12,838 & 5973 \\
High & 5 & \\
\hline
\end{tabular}

randomly pick a child from two separate clusters, a child with a higher probability of complete vaccination in the cluster had a 1.45 times higher probability of being completely vaccinated for the basic vaccines than a child with lower childhood vaccinations in the cluster. as it

Table 2 Child and maternal-related characteristics of children aged 12-23 months in 12 East African countries

\begin{tabular}{|c|c|c|}
\hline Variables & Frequency & Percentage (\%) \\
\hline \multicolumn{3}{|l|}{ Place of delivery } \\
\hline Home & 5019 & 26.7 \\
\hline Health facility & 13,792 & 73.3 \\
\hline \multicolumn{3}{|l|}{ ANC visit } \\
\hline No & 1318 & 7.0 \\
\hline $1-3$ & 6901 & 36.7 \\
\hline$\geq 4$ & 10,592 & 56.3 \\
\hline \multicolumn{3}{|l|}{ PNC visit } \\
\hline No & 13,177 & 70.0 \\
\hline Yes & 5634 & 30.0 \\
\hline \multicolumn{3}{|l|}{ Parity } \\
\hline $1-3$ & 11,147 & 59.3 \\
\hline $4-6$ & 5420 & 28.8 \\
\hline$\geq 7$ & 2244 & 11.9 \\
\hline \multicolumn{3}{|l|}{ Child size at birth } \\
\hline Large & 5323 & 28.3 \\
\hline Average & 8634 & 45.9 \\
\hline Small & 4854 & 25.8 \\
\hline \multicolumn{3}{|l|}{ Mode of delivery } \\
\hline Caesarean delivery & 1172 & 6.2 \\
\hline Vaginal delivery & 17,639 & 93.8 \\
\hline \multicolumn{3}{|c|}{ Birth interval (in months) } \\
\hline$<24$ & 2303 & 12.2 \\
\hline $24-48$ & 7911 & 42.1 \\
\hline$>48$ & 8597 & 45.7 \\
\hline
\end{tabular}

has the smallest variance value, the final model was the best-fitted model. The PCV in the final model was 0.47 , which showed that about $47 \%$ of the total variability in the complete basic childhood vaccination was explained by the full model (Table 3 ).

In the multivariable multilevel logistic regression analysis; maternal age, maternal education, husband education, media exposure, preceding birth interval, number of ANC visit, PNC visit, place of delivery, child-size at birth, parity wealth status, country, and community poverty were significant associated with complete basic childhood vaccinations.

Mothers aged 25-34 years and $\geq 35$ years were 1.21 times $(\mathrm{AOR}=1.21,95 \% \mathrm{CI}: 1.10,1.32)$ and 1.50 times $(\mathrm{AOR}=1.50,95 \% \mathrm{CI}: 1.31,1.71)$ higher odds of completely vaccinated their children compared to mothers aged 15-24 years, respectively. Children born to mother who attained primary education, and secondary education and above had 1.26 times $(\mathrm{AOR}=1.26,95 \% \mathrm{CI}$ : $1.15,1.38)$ and 1.54 times $(\mathrm{AOR}=1.54,95 \% \mathrm{CI}: 1.36$, 1.75) higher likelihood of completely vaccinated than children whose mother did not have formal education, respectively. The odds of being completely vaccinated among children whose father attained primary education, and secondary and above were 1.25 times $(\mathrm{AOR}=$ 1.25, 95\% CI: $1.13,1.39)$ and 1.24 times $(\mathrm{AOR}=1.24$, 95\% CI: 1.11, 1.40) higher than children whose father had no education, respectively. Mothers who had media exposure were 1.23 times (AOR $=1.23,95 \% \mathrm{CI}$ : 1.13 , 1.33) higher odds of completely vaccinating their children than children born to mothers who didn't have media exposure. Children born at preceding birth interval of 24-48 months, and greater than 48 months were 1.28 times $(\mathrm{AOR}=1.28,95 \% \mathrm{CI}: 1.15,1.42)$ and 1.35 times $(\mathrm{AOR}=1.35,95 \% \mathrm{CI}: 1.21,1.50)$ times higher odds of being completely vaccinated than children born less than 24 months of preceding birth, respectively. A child born to mothers who had 1-3 ANC visit, and four and above $\mathrm{ANC}$ visit was 3.24 times $(\mathrm{AOR}=3.24,95 \% \mathrm{CI}$ : 

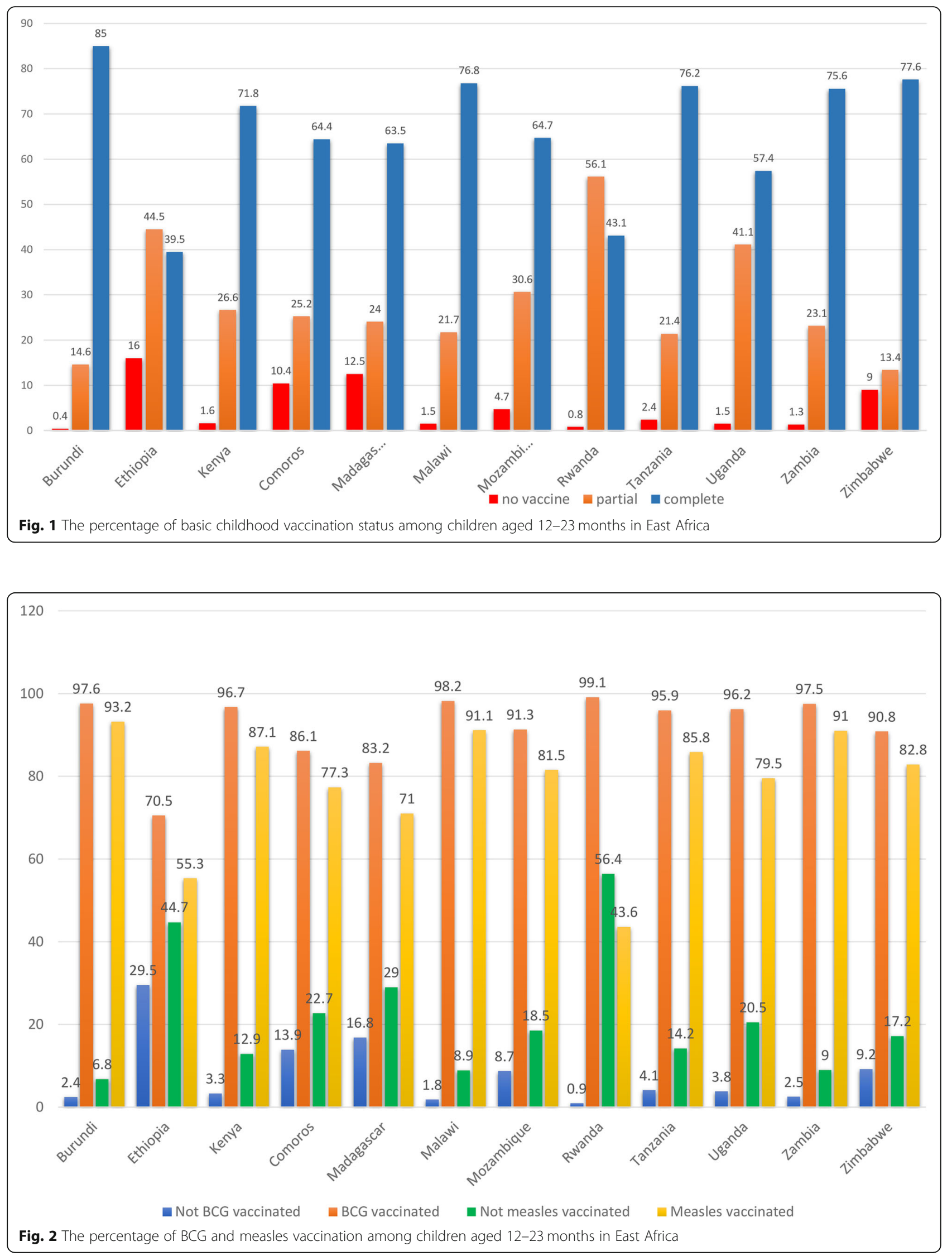


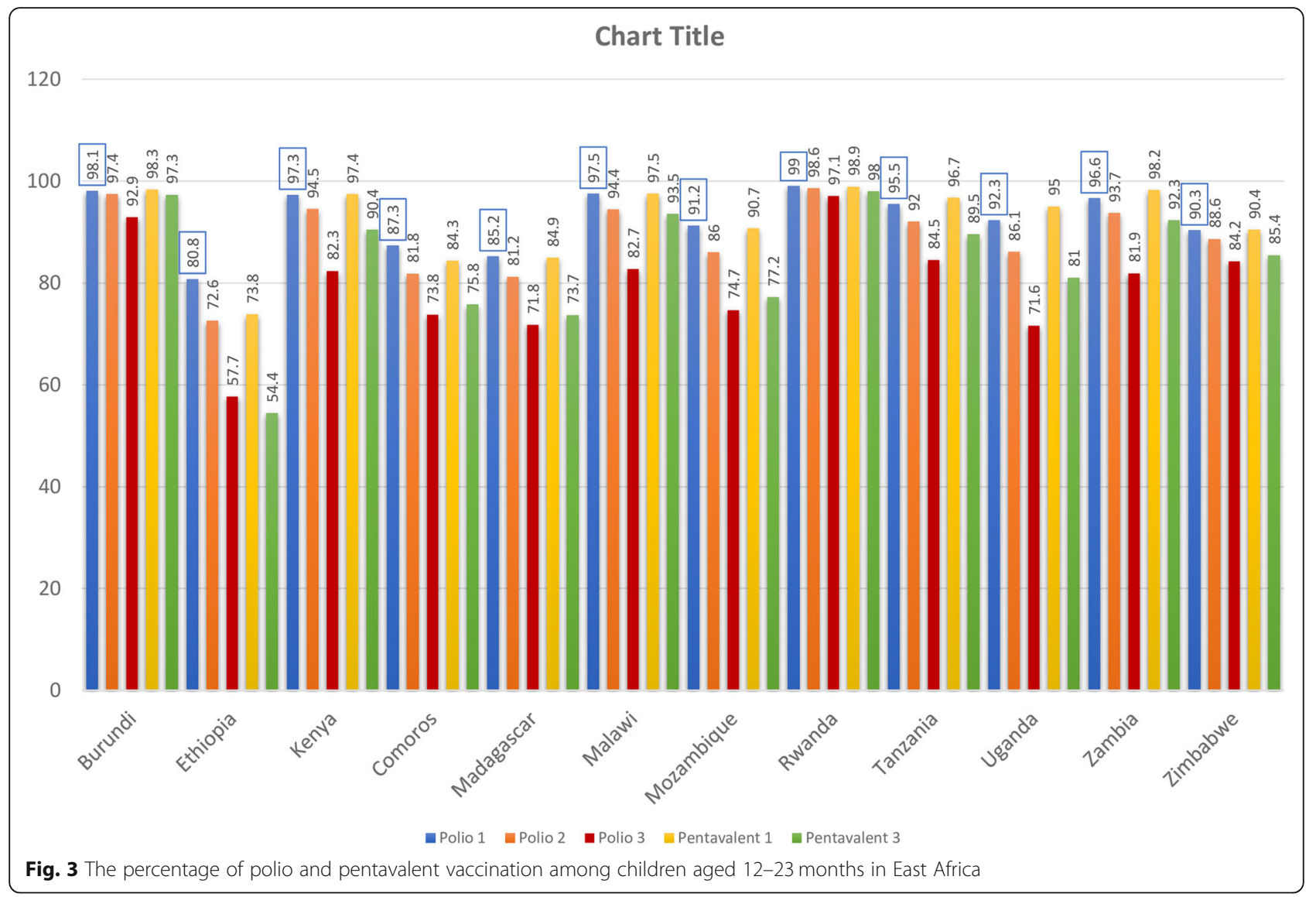

$2.78,3.77)$ and 3.68 times $(\mathrm{AOR}=3.68,95 \% \mathrm{CI}: 3.17$, 4.28) more likelihood of taking complete vaccination than a child born to mother who did not have ANC visit, respectively.

A mother who had a PNC visit was 1.34 times (AOR = 1.34, 95\% CI: $1.23,1.47$ ) higher odds of completely vaccinating their child compared to a mother who did not have a PNC visit, and a mother who gave birth at a health facility had 1.48 times $(\mathrm{AOR}=1.48,95 \% \mathrm{CI}$ : 1.35 , 1.62) higher likelihood of completely vaccinating their children than mother who had home delivery. Mother whose child was average size at birth was 1.09 times (AOR $=1.09,95 \% \mathrm{CI}: 1.01,1.19)$ increased odds of completely vaccinating their children than whose child was large size at birth. The odds of complete vaccination among children born to mother who had 4-6 birth, and above six births were decreased by $17 \% \quad(\mathrm{AOR}=0.83$, 95\% CI: $0.75,0.91$ ) and 40\% (AOR $=0.60,95 \%$ CI: 0.52 , $0.70)$ compared to children born to mother who had 13 births, respectively. Regarding wealth status, children from the middle and rich households were 1.16 times $(\mathrm{AOR}=1.16,95 \% \mathrm{CI}: 1.06,1.28)$ and 1.20 times $(\mathrm{AOR}=$ 1.20 , 95\% CI: 1.09, 1.33) higher odds of complete vaccination compared to children in the poor household wealth respectively.
Among community-level factors; children in Burundi, Kenya, Madagascar, Malawi, Mozambique, Rwanda, Tanzania, Zambia, and Zimbabwe were 4.21 (AOR = 4.21, 95\% CI: 3.47, 5.11), 1.96 (AOR = 1.96, 95\% CI: 1.69, 2.27), $1.48(\mathrm{AOR}=1.48,95 \% \mathrm{CI}: 1.24,1.76), 2.08(\mathrm{AOR}=$ 2.08, 95\% CI: $1.72,2.52), 1.60(\mathrm{AOR}=1.60,95 \% \mathrm{CI}$ : 1.37, 1.86), $0.41(\mathrm{AOR}=0.41,95 \% \mathrm{CI}: 0.34,0.50), 2.10$ $(\mathrm{AOR}=2.10,95 \% \mathrm{CI}: 1.79,2.46), 1.77(\mathrm{AOR}=1.77,95 \%$ CI: $1.50,2.10)$ and $1.83(\mathrm{AOR}=1.83,95 \% \mathrm{CI}: 1.49,2.26)$ times higher odds of complete vaccination compared to children in Ethiopia respectively. Children in the community with low poverty had 1.21 times $(\mathrm{AOR}=1.21$, $95 \%$ CI: $1.11,1.32$ ) higher odds of complete vaccination compared to children in the community with high poverty (Table 3 ).

\section{Discussion}

Complete basic childhood vaccination status in East Africa according to the WHO vaccination schedule was low. Childhood full basic vaccination coverage among children aged 12-23 months in East Africa was 69.21\% (95\% CI: 69.20, 69.21\%), which significantly varied across countries. That may be because of inequalities in access to immunization programs and the views of populations about the value of childhood immunization [48]. In East 
Table 3 Multilevel analysis of individual and community level factors of complete basic childhood vaccination among children aged 12-23 months in East Africa

\begin{tabular}{lllll}
\hline Variable & $\begin{array}{l}\text { Null model (model without } \\
\text { independent variables) }\end{array}$ & $\begin{array}{l}\text { Model } 1 \text { (model adjusted with } \\
\text { individual level variables) } \\
\text { AOR with } 95 \% \mathrm{Cl}\end{array}$ & $\begin{array}{l}\text { Model } 2 \text { (model adjusted } \\
\text { with community level } \\
\text { variables) AOR with } 95 \% \mathrm{Cl}\end{array}$ & $\begin{array}{l}\text { Model } 3 \text { (model adjusted with } \\
\text { individual and community level } \\
\text { variables) AOR with } 95 \% \mathrm{Cl}\end{array}$ \\
\hline
\end{tabular}

\section{Maternal age}

$\begin{array}{ll}15-24 & 1 \\ 25-34 & 1.13(1.03,1.23) \\ \geq 35 & 1.41(1.24,1.61)\end{array}$

$1.21(1.10,1.32)^{*}$

$1.50(1.31,1.71)^{*}$

Maternal education

No

Primary

1

$1.22(1.12,1.33)$

Secondary and

$1.52(1.35,1.72)$

above

Husband education

No

Primary

Secondary and

above

$1.26(1.14,1.40)$

$1.37(1.22,1.53)$

Media exposure

No

1

$1.15(1.06,1.24)$

Yes

Preceding birth interval (in months)

$$
\begin{aligned}
& <24 \\
& 24-48
\end{aligned}
$$$$
\geq 49
$$

$1.34(1.21,1.48)$

$1.34(1.20,1.49)$

\section{Number of ANC visit}

No visit

$1-3$

$\geq 4$

PNC visit

No

Yes

Place of delivery

Home

Health facility

Mode of delivery

Vaginal

Caesarean

Child size at birth

Large

Average

Small

Parity

$1-3$

$4-6$

$\geq 7$
1

$3.82(3.30,4.42)$

$4.33(3.74,5.01)$

\section{1}

$1.41(1.30,1.52)$

1

$1.52(1.40,1.64)$

1

$0.97(0.84,1.13)$

$1.14(1.06,1.24)$

$1.05(0.96,1.15)$

1

$0.88(0.80,0.96)$

$0.64(0.56,0.74)$
1

$1.26(1.15,1.38)^{*}$

$1.54(1.36,1.75)^{*}$

1

$1.25(1.13,1.39)^{*}$

$1.24(1.11,1.40)^{*}$

1

$1.23(1.13,1.33)^{* *}$

1

$1.28(1.15,1.42)^{*}$

$1.35(1.21,1.50)^{*}$

1

$3.24(2.78,3.77)^{*}$

$3.68(3.17,4.28)^{* *}$

1

$1.34(1.23,1.47)^{*}$

1

$1.48(1.35,1.62)^{* *}$

1

$1.05(0.90,1.22)$

1

$1.09(1.01,1.19)^{* *}$

$0.99(0.91,1.10)$

1

$0.83(0.75,0.91)^{*}$

$0.60(0.52,0.70)^{*}$

Marital status 
Table 3 Multilevel analysis of individual and community level factors of complete basic childhood vaccination among children aged 12-23 months in East Africa (Continued)

\begin{tabular}{|c|c|c|c|c|}
\hline Variable & $\begin{array}{l}\text { Null model (model without } \\
\text { independent variables) }\end{array}$ & $\begin{array}{l}\text { Model } 1 \text { (model adjusted with } \\
\text { individual level variables) } \\
\text { AOR with } 95 \% \mathrm{Cl}\end{array}$ & $\begin{array}{l}\text { Model } 2 \text { (model adjusted } \\
\text { with community level } \\
\text { variables) AOR with } 95 \% \mathrm{Cl}\end{array}$ & $\begin{array}{l}\text { Model } 3 \text { (model adjusted with } \\
\text { individual and community leve } \\
\text { variables) AOR with } 95 \% \mathrm{Cl}\end{array}$ \\
\hline Single & & 1 & & 1 \\
\hline Married & & $1.19(1.02,1.39)$ & & $1.14(0.97,1.33)$ \\
\hline $\begin{array}{l}\text { Divorced/ } \\
\text { widowed/ } \\
\text { separated }\end{array}$ & & $0.88(0.74,1.06)$ & & $0.85(0.71,1.08)$ \\
\hline \multicolumn{5}{|l|}{ Wealth status } \\
\hline Poor & & 1 & & 1 \\
\hline Middle & & $1.22(1.11,1.33)$ & & $1.16(1.06,1.28)^{*}$ \\
\hline Average & & $1.21(1.11,1.32)$ & & $1.20(1.09,1.33)^{* *}$ \\
\hline \multicolumn{5}{|l|}{ Country } \\
\hline Ethiopia & & & 1 & 1 \\
\hline Burundi & & & $7.76(6.48,9.31)$ & $4.21(3.47,5.11)^{*}$ \\
\hline Kenya & & & $3.04(2.68,3.46)$ & $1.96(1.69,2.27)^{*}$ \\
\hline Comoros & & & $2.07(1.69,2.52)$ & $1.17(0.94,1.45)$ \\
\hline Madagascar & & & $2.12(1.81,2.48)$ & $1.48(1.24,1.76)^{*}$ \\
\hline Malawi & & & $4.92(4.13,5.87)$ & $2.08(1.72,2.52)^{*}$ \\
\hline Mozambique & & & $2.76(2.41,3.15)$ & $1.60(1.37,1.86)^{*}$ \\
\hline Rwanda & & & $1.01(0.84,1.19)$ & $0.41(0.34,0.50)^{*}$ \\
\hline Tanzania & & & $4.17(3.62,4.79)$ & $2.10(1.79,2.46)^{*}$ \\
\hline Uganda & & & $1.85(1.57,2.18)$ & $0.91(0.76,1.09)$ \\
\hline Zambia & & & $4.09(3.54,4.73)$ & $1.77(1.50,2.10)^{*}$ \\
\hline Zimbabwe & & & $5.05(4.22,6.05)$ & $1.83(1.49,2.26)^{*}$ \\
\hline \multicolumn{5}{|l|}{ Residence } \\
\hline Rural & & & 1 & 1 \\
\hline Urban & & & $1.48(1.36,1.60)$ & $0.92(0.84,1.02)$ \\
\hline \multicolumn{5}{|c|}{ Community women education } \\
\hline Low & & & 1 & 1 \\
\hline High & & & $1.21(1.09,1.34)$ & $0.99(0.89,1.11)$ \\
\hline \multicolumn{5}{|c|}{ Community poverty } \\
\hline Low & & & $1.39(1.27,1.51)$ & $1.21(1.11,1.32)^{* *}$ \\
\hline High & & & 1 & 1 \\
\hline \multicolumn{5}{|c|}{ Community media exposure } \\
\hline Low & & & 1 & 1 \\
\hline High & & & $1.09(0.99,1.20)$ & $0.97(0.88,1.07)$ \\
\hline \multicolumn{5}{|c|}{ Random effect analysis result } \\
\hline $\begin{array}{l}\text { Cluster level } \\
\text { variance }\end{array}$ & $0.15(0.11,0.19)$ & $0.09(0.06,0.14)$ & $0.13(0.09,0.17)$ & $0.08(0.06,0.12)$ \\
\hline ICC & $0.42(0.33,0.55)$ & $0.28(0.19,0.39)$ & $0.38(0.28,0.51)$ & $0.27(0.19,0.40)$ \\
\hline LR-test & $\begin{array}{l}\text { chibar2 }(01)=115.38 p- \\
\text { value }<0.0001\end{array}$ & $\begin{array}{l}\text { chibar2 }(01)=48.85 p \text {-value }< \\
0.0001\end{array}$ & $\begin{array}{l}\text { chibar2(01) =83.03 P-value }< \\
0.001\end{array}$ & $\begin{array}{l}\text { chibar2(01) }=84.51 p \text {-value }< \\
0.0001\end{array}$ \\
\hline MOR & $1.45(1.38,1.51)$ & $1.33(1.26,1.43)$ & $1.40(1.33,1.48)$ & $1.31(1.26,1.39)$ \\
\hline PCV & Ref & 0.4 & 0.13 & 0.47 \\
\hline LLR & $-11,725.223$ & $-10,792.516$ & $-11,029.99$ & $-10,437.633$ \\
\hline
\end{tabular}


Table 3 Multilevel analysis of individual and community level factors of complete basic childhood vaccination among children aged 12-23 months in East Africa (Continued)

\begin{tabular}{lllll}
\hline Variable & $\begin{array}{l}\text { Null model (model without } \\
\text { independent variables) }\end{array}$ & $\begin{array}{l}\text { Model } \mathbf{1} \text { (model adjusted with } \\
\text { individual level variables) } \\
\text { AOR with } \mathbf{9 5 \%} \mathrm{Cl}\end{array}$ & $\begin{array}{l}\text { Model } \mathbf{2} \text { (model adjusted } \\
\text { with community level } \\
\text { variables) AOR with 95\% Cl }\end{array}$ & $\begin{array}{l}\text { Model } \mathbf{3} \text { (model adjusted with } \\
\text { individual and community level } \\
\text { variables) AOR with 95\% Cl }\end{array}$ \\
\hline Deviance & $23,450.446$ & $21,585.032$ & $22,059.98$ & $20,875.266$ \\
\hline
\end{tabular}

${ }^{*} p$-value $<0.05,{ }^{* *} p$-value $<0.01$, AOR Adjusted Odds Ratio, CI Confidence Interval, ICC Intra-class Correlation Coefficient, LLR Log-likelihood Ratio, LR Likelihood

Ratio, MOR Median Odds Ratio, PCV Proportional Change in Variance

African countries, the ongoing conflict and persistent political instability played an important role in hindering vaccination coverage; the literature showed that lack of safety played a major role in reducing vaccination coverage, especially in remote areas [49]. Besides, there was a high proportion of children vaccinated for BCG, polio 1 , and pentavalent 1 , but a substantial decline in the proportion of children vaccinated for polio 3 , pentavalent 3 , and measles. This may be related to vaccine hesitancy in developing countries being a common contributing factor to incomplete vaccination [50]. Cultural misconceptions, adverse effects of vaccinations, and associated consequences could emanate from the root causes of vaccine hesitancy [51]. Also, inadequate management of the adverse effects of vaccinations during regular and supplemental immunization activities may be the reason for not vaccinating their children. For example, measles is often related to mild reactions and is manifested by fever, abscess of the injection site, and irritability [52].

In the multilevel analysis; maternal age, maternal education, husband education, media exposure, preceding birth interval, number of ANC visit, PNC visit, place of delivery, child-size at birth, parity, wealth index, country, and community poverty were significantly associated with complete basic childhood vaccination. Mothers aged 25 and above were more likely than mothers aged 19-24 to completely vaccinate their children. It was consistent with a study reported in Nigeria [27], it may be attributed to the corresponding improvement in the usage of maternal health care services such as ANC visit, health facility delivery, and PNC visit as the entry point for childhood vaccination, as the maternal age rises [53, 54]. Besides, they are aware of lethal childhood diseases that can be avoided by basic vaccinations as the age of the mother rises $[55,56]$.

In this study, maternal education and husband education were significant predictors of complete basic childhood vaccination. Educated mothers and husbands had higher odds of completely vaccinating their children than uneducated women and husbands. It was in line with studies reported in Nigeria [57], India [58], Indonesia [33], and Turkey [59]. The potential reason may be that maternal and husband education is essential to enhancing the use of primary care services such as childhood vaccination services and increased awareness of childhood immunization [60]. Besides, educated mothers had improved health care decision making autonomy to utilize maternal health care services [61].

Media exposure was significantly associated with increased odds of full childhood vaccination, and it was consistent with studies in Bangladesh [35] and the Democratic Republic of Congo [62]. Media exposure is the most potent health promotion strategy to access the community easily to improve healthcare-seeking behavior [63]. Media exposure plays an essential role in disseminating information about childhood vaccination and allowing behavioral change towards childhood vaccination practices [64].

A mother who used maternal health care services (ANC visit, health facility delivery, and PNC visit) had higher odds of fully childhood vaccination than women who did not use it. It was supported by studies reported in Ghana [65], Senegal [66], and Pakistan [67], it might be due to women who had ANC follow up, health facility delivery, and PNC visit might get counseling service about vaccination [68]. Besides, children born at health facilities get BCG and polio 0 vaccines at birth and get information about the basic childhood vaccination services with their corresponding schedules [69]. This might be the possible reason for the higher odds of full basic childhood vaccinations in women who use maternal health care services during pregnancy, delivery, and delivery.

Women who gave birth before 24 months of preceding birth had lower odds of fully vaccinating their child than women gave birth at 24 months and above. This was consistent with studies in rural Bangladesh [35] and Nigeria [70]. Shorter birth spacing has been associated with increased financial, mental, and psychological consequences to the mothers, and therefore mothers might not use childhood vaccination services [71]. Children who were average size at birth had higher odds of fully immunized compared to children who were large size at birth. It was a consistent study in Nigeria [72], it could be due to mothers who gave average size child at birth are more of interested to keep their child healthy and visit child health care services such as immunization programs than women who gave large size child at birth since the delivery are more of complicated this might hinder their childhood vaccination services utilization $[45,73]$. Multiparous women had higher odds of fully vaccinated their children than primiparous women. It 
was consistent with study findings [74, 75], it might be due to parity is a proxy for the women's accumulated knowledge of maternal healthcare services utilization from their previous experience, which may have a positive influence on the acceptance of full immunization of children [35, 76].

Children from rich household wealth and low community poverty were more likely to be fully immunized than children from poor household wealth and high community poverty. It supported by previous studies [30, 77, 78], though immunization provided by the EPI program is free, and public efforts to access vulnerable mothers and infants are continued, it might be due to an increase in child care practice, better health-seeking behavior, and health care access among wealthier households [79].

This study has strengths and limitations. This study was based on a pooled nationally representative DHS survey in 12 East African countries that were weighted, and multilevel analysis was done to get a reliable estimate and standard error. Besides, this study was based on a large sample size that had adequate power to detect the true effect of the independent variables. As a limitation, since the study used cross-sectional data, we cannot establish a causal relationship between complete basic childhood vaccination and the identified independent variables. Secondly, Information about the basic vaccinations was collected based on mothers' verbal responses, besides reviewing vaccination cards. This might cause a lot recall bias since full vaccination status includes BCG, 3 pentavalent, 3 polio and measles vaccines that may overestimate/underestimate the findings.

\section{Conclusion}

Complete basic childhood vaccination coverage remains a major public health problem in East Africa with significant variation across countries. Complete basic childhood vaccination was lower than WHO and UNICEF goals, and it needs substantial progress in improving childhood vaccination and narrowing the gap across countries. Maternal age, maternal education, husband education, media exposure, preceding birth interval, number of ANC visits, PNC visits, place of delivery, child-size at birth, parity, wealth index, country, and community poverty were significant predictors of complete basic childhood immunization. Therefore, public health interventions targeting uneducated mothers and fathers, poor households, and who didn't use maternal health care services to improve complete childhood vaccination to enhance child survival.

\section{Abbreviations}

ANC: Antenatal Care; DPT: Diphtheria, Pertussis, and Tetanus;

EA: Enumeration Area; DHS: Demography and Health Survey; EPI: Expanded Program of Immunization; ICC: Intra-class Correlation Coefficient; MOR: Median Odds Ratio; PCV: Proportional Change in Variance;
PNC: Postnatal Care; SSA: Sub-Saharan Africa; WHO: World Health Organization

\section{Acknowledgments}

The authors would like to thank MEASURE DHS for sharing the data for further analysis. We are also grateful to thank others who are directly or indirectly involved during the preparation of this manuscript.

\section{Authors' contributions}

GAT, ZTT, KST and ABT conceived the study, involved in the study design, data analysis, drafted and critically reviewed the manuscript. All authors read and approved the final manuscript.

\section{Funding}

This research received no specific grant from any funding agency in the public, commercial or not-for-profit sectors.

\section{Availability of data and materials}

The datasets used during the current study are available at Measure DHS website: http://www.measuredhs.com.

\section{Ethics approval and consent to participate}

The DHS data is available to the general public by request in different formats from the Measure DHS website http://www.measuredhs.com. We submitted a request to the measure DHS by briefly stating the objectives of this analysis and thereafter received permission to download the maternal and children's dataset in STATA format.

\section{Consent for publication}

Not applicable as there is no image or other confidentiality related issues.

\section{Competing interests}

The authors declare that they have no competing interests.

Received: 6 August 2020 Accepted: 24 November 2020

Published online: 01 December 2020

\section{References}

1. Bray F, Ferlay J, Soerjomataram I, Siegel RL, Torre LA, Jemal A. Global cancer statistics 2018: GLOBOCAN estimates of incidence and mortality worldwide for 36 cancers in 185 countries. CA Cancer J Clin. 2018;68(6):394-424.

2. Brockerhoff $M$, Hewett $P$. Inequality of child mortality among ethnic groups in sub-Saharan Africa. Bull World Health Organ. 2000;78:30-41.

3. Kinney MV, Kerber KJ, Black RE, Cohen B, Nkrumah F, Coovadia H, et al. SubSaharan Africa's mothers, newborns, and children: where and why do they die? PLoS Med. 2010;7(6):se1000294.

4. Ki-Moon B. Global strategy for women's and children's health. New York: United Nations; 2010.

5. UNICEF. The state of the world's children 2008: Child survival: Unicef; 2007.

6. Olusegun OL, Ibe RT, Micheal IM. Curbing maternal and child mortality: the Nigerian experience. Int J Nurs Midwifery. 2012;4(3):33-9.

7. Rudan I, Nair H, Marušić A, Campbell H. Reducing mortality from childhood pneumonia and diarrhoea: The leading priority is also the greatest opportunity. J Global Health. 2013;3(1).

8. Chopra M, Mason E, Borrazzo J, Campbell H, Rudan I, Liu L, et al. Ending of preventable deaths from pneumonia and diarrhoea: an achievable goal. Lancet. 2013:381(9876):1499-506.

9. Leung DT, Chisti MJ, Pavia AT. Prevention and control of childhood pneumonia and diarrhea. Pediatr Clin. 2016;63(1):67-79.

10. Ehreth J. The global value of vaccination. Vaccine. 2003;21(7-8):596-600.

11. Miller MA, Sentz JT. Vaccine-preventable diseases. Disease and Mortality in Sub-Saharan Africa 2nd edition: The International Bank for Reconstruction and Development/The World Bank; 2006.

12. Greenwood B. The contribution of vaccination to global health: past, present and future. Philosophical Transactions Royal Soc B: Biol Sci. 2014; 369(1645):20130433.

13. Kane M, Lasher H. Childhood immunization. Occas Pap. 2002.

14. Oliwa JN, Marais BJ. Vaccines to prevent pneumonia in children-a developing country perspective. Paediatr Respir Rev. 2017;22:23-30. 
15. Whitney CG, Zhou F, Singleton J, Schuchat A. Benefits from immunization during the vaccines for children program era-United States, 1994-2013. MMWR Morb Mortal Wkly Rep. 2014;63(16):352.

16. Organization WH. Expanded programme on immunization. Weekly Epidemiological Record= Relevé épidémiologique hebdomadaire. 1984; 59(12):85-9.

17. Neonatal, infant, and under-5 mortality and morbidity burden in the Eastern Mediterranean region: findings from the Global Burden of Disease 2015 study. Int J Public Health. 2018;63:63-77.

18. Organization WH. Levels and trends in child mortality: report 2019: The World Bank; 2019.

19. Yaya S, Uthman OA, Okonofua F, Bishwajit G. Decomposing the rural-urban gap in the factors of under-five mortality in sub-Saharan Africa? Evidence from 35 countries. BMC Public Health. 2019;19(1):616.

20. Babinard J, Roberts P. Maternal and child mortality development goals: what can the transport sector do? 2006

21. Peck M, Gacic-Dobo M, Diallo MS, Nedelec Y, Sodha SS, Wallace AS. Global routine vaccination coverage, 2018. Morb Mortal Wkly Rep. 2019;68(42):937.

22. Anand S, Bärnighausen T. Health workers and vaccination coverage in developing countries: an econometric analysis. Lancet. 2007;369(9569):1277-85.

23. Peck M, Gacic-Dobo M, Diallo MS, Nedelec Y, Sodha SS, Wallace AS. Global routine vaccination coverage, 2018/Couverture de la vaccination systematique dans le monde, 2018. Wkly Epidemiol Rec. 2019;94(43):498-505.

24. de la Santé Mondiale O, Organization WH. Global routine vaccination coverage, 2018-Couverture de la vaccination systématique dans le monde, 2018. Weekly Epidemiological Record= Relevé épidémiologique hebdomadaire. 2019;94(43):498-504.

25. Etana B, Deressa W. Factors associated with complete immunization coverage in children aged 12-23 months in ambo Woreda, Central Ethiopia. BMC Public Health. 2012;12(1):566.

26. Antai D. Faith and child survival: the role of religion in childhood immunization in Nigeria. J Biosoc Sci. 2009;41(1):57.

27. Oleribe O, Kumar V, Awosika-Olumo A, Taylor-Robinson SD. Individual and socioeconomic factors associated with childhood immunization coverage in Nigeria. Pan Afr Med J. 2017;26.

28. Wiysonge CS, Uthman OA, Ndumbe PM, Hussey GD. Individual and contextual factors associated with low childhood immunisation coverage in sub-Saharan Africa: a multilevel analysis. PLoS One. 2012;7(5):e37905.

29. Anokye R, Acheampong E, Budu-Ainooson A, Edusei AK, Okyere P, Dogbe J, et al. Socio-demographic determinants of childhood immunization incompletion in Koforidua, Ghana. BMC Res Notes. 2018;11(1):656.

30. Tamirat KS, Sisay MM. Full immunization coverage and its associated factors among children aged 12-23 months in Ethiopia: further analysis from the 2016 Ethiopia demographic and health survey. BMC Public Health. 2019;19(1):1019.

31. Kusuma YS, Kumari R, Pandav CS, Gupta SK. Migration and immunization: determinants of childhood immunization uptake among socioeconomically disadvantaged migrants in Delhi. India Tropical Med Int Health. 2010;15(11): 1326-32.

32. Boulton ML, Carlson BF, Power LE, Wagner AL. Socioeconomic factors associated with full childhood vaccination in Bangladesh, 2014. Int J Infect Dis. 2018;69:35-40.

33. Streatfield $K$, Singarimbun M, Diamond I. Maternal education and child immunization. Demography. 1990;27(3):447-55.

34. Rammohan A, Awofeso N, Fernandez RC. Paternal education status significantly influences infants' measles vaccination uptake, independent of maternal education status. BMC Public Health. 2012;12(1):336.

35. Rahman M, Obaida-Nasrin S. Factors affecting acceptance of complete immunization coverage of children under five years in rural Bangladesh. Salud Publica Mex. 2010;52:134-40.

36. Wondimu A, Cao Q, Wilschut JC, Postma MJ. Factors associated with the uptake of newly introduced childhood vaccinations in Ethiopia: the cases of rotavirus and pneumococcal conjugate vaccines. BMC Public Health. 2019;19(1):1656.

37. Negussie A, Kassahun W, Assegid S, Hagan AK. Factors associated with incomplete childhood immunization in Arbegona district, southern Ethiopia: a case-control study. BMC Public Health. 2015;16(1):27.

38. Fatiregun AA, Okoro AO. Maternal determinants of complete child immunization among children aged 12-23 months in a southern district of Nigeria. Vaccine. 2012;30(4):730-6.

39. Singh K, Haney E, Olorunsaiye C. Maternal autonomy and attitudes towards gender norms: associations with childhood immunization in Nigeria. Matern Child Health J. 2013;17(5):837-41.
40. Gavrielov-Yusim N, Battat E, Neumann L, Friger M, Balicer RD. Birth order and private voluntary immunization - a study of 110,902 children. Vaccine. 2012;30(2):442-7.

41. Kassab M, Hamadneh S, Nuseir K, ALmomani B, Hamadneh J. Factors associated with infant pain severity undergoing immunization injections. J Pediatr Nurs. 2018:42:e85-90.

42. Bbaale E. Factors influencing childhood immunization in Uganda. J Health Population Nutrition. 2013;31(1):118.

43. Abadura SA, Lerebo WT, Kulkarni U, Mekonnen ZA. Individual and community level determinants of childhood full immunization in Ethiopia: a multilevel analysis. BMC Public Health. 2015;15(1):972.

44. Cowgill KD, Ndiritu M, Nyiro J, Slack MP, Chiphatsi S, Ismail A, et al. Effectiveness of Haemophilus influenzae type $b$ conjugate vaccine introduction into routine childhood immunization in Kenya. Jama. 2006; 296(6):671-8.

45. Lakew $Y$, Bekele A, Biadgilign S. Factors influencing full immunization coverage among 12-23 months of age children in Ethiopia: evidence from the national demographic and health survey in 2011. BMC Public Health. 2015;15(1):728.

46. Rodriguez G, Elo I. Intra-class correlation in random-effects models for binary data. Stata J. 2003;3(1):32-46.

47. Merlo J, Chaix B, Ohlsson H, Beckman A, Johnell K, Hjerpe P, et al. A brief conceptual tutorial of multilevel analysis in social epidemiology: using measures of clustering in multilevel logistic regression to investigate contextual phenomena. J Epidemiol Community Health. 2006;60(4):290-7.

48. Ozawa S, Clark S, Portnoy A, Grewal S, Brenzel L, Walker DG. Return on investment from childhood immunization in low-and middle-income countries, 2011-20. Health Aff. 2016;35(2):199-207.

49. Tugumisirize F, Tumwine J, Mworoza E. Missed opportunities and caretaker constraints to childhood vaccination in rural areas of Uganda. East Afr Med J. 2002;79(7):347-54

50. Dube E, Vivion M, MacDonald NE. Vaccine hesitancy, vaccine refusal and the anti-vaccine movement: influence, impact and implications. Expert Rev Vaccines. 2015;14(1):99-117.

51. Dubé E, Laberge C, Guay M, Bramadat P, Roy R, Bettinger JA. Vaccine hesitancy: an overview. Human Vaccines Immunotherap. 2013;9(8):1763-73.

52. Pugliese-Garcia M, Heyerdahl LW, Mwamba C, Nkwemu S, Chilengi R, Demolis $R$, et al. Factors influencing vaccine acceptance and hesitancy in three informal settlements in Lusaka. Zambia Vaccine. 2018;36(37):5617-24.

53. Sondaal SFV, Browne JL, Amoakoh-Coleman M, Borgstein A, Miltenburg AS, Verwijs $M$, et al. Assessing the effect of $m$ Health interventions in improving maternal and neonatal care in low-and middle-income countries: a systematic review. PLoS One. 2016;11(5):e0154664.

54. Atnafu A, Otto $\mathrm{K}$, Herbst $\mathrm{CH}$. The role of mHealth intervention on maternal and child health service delivery: findings from a randomized controlled field trial in rural Ethiopia. Mhealth. 2017;3.

55. Control CfD, Prevention, Program NI, Prevention. Epidemiology and prevention of vaccine-preventable diseases: Department of Health \& Human Services, Public Health Service, Centers for ... ; 2005.

56. Feyisetan BJ, Asa S, Ebigbola JA. Mothers' management of childhood diseases in Yorubaland: the influence of cultural beliefs. Health Transition Rev. 1997;7(2):221-34.

57. Burroway R, Hargrove A. Education is the antidote: individual-and community-level effects of maternal education on child immunizations in Nigeria. Soc Sci Med. 2018;213:63-71.

58. Vikram K, Vanneman R, Desai S. Linkages between maternal education and childhood immunization in India. Soc Sci Med. 2012;75(2):331-9.

59. Özer M, Fidrmuc J, Eryurt MA. Maternal education and childhood immunization in Turkey. Health Econ. 2018;27(8):1218-29.

60. Owais A, Hanif B, Siddiqui AR, Agha A, Zaidi AK. Does improving maternal knowledge of vaccines impact infant immunization rates? A community-based randomized-controlled trial in Karachi, Pakistan. BMC Public Health. 2011;11(1):239.

61. Bloom SS, Wypij D, Gupta MD. Dimensions of women's autonomy and the influence on maternal health care utilization in a north Indian city. Demography. 2001;38(1):67-78.

62. Acharya P, Kismul H, Mapatano MA, Hatløy A. Individual-and communitylevel determinants of child immunization in the Democratic Republic of Congo: a multilevel analysis. PLoS One. 2018;13(8):e0202742.

63. Nutbeam D. Health literacy as a public health goal: a challenge for contemporary health education and communication strategies into the $21 \mathrm{st}$ century. Health Promot Int. 2000;15(3):259-67. 
64. Lee HO, Kim S. Linking health information seeking to behavioral outcomes: antecedents and outcomes of childhood vaccination information seeking in South Korea. J Health Commun. 2015;20(3):285-96.

65. Laryea DO, Parbie EA, Frimpong E. Timeliness of childhood vaccine uptake among children attending a tertiary health service facility-based immunisation clinic in Ghana. BMC Public Health. 2014:14(1):1-5.

66. Sarker AR, Akram R, Ali N, Chowdhury Zl, Sultana M. Coverage and determinants of full immunization: vaccination coverage among Senegalese children. Medicina. 2019;55(8):480

67. Noh J-W, Kim Y-M, Akram N, Yoo K-B, Park J, Cheon J, et al. Factors affecting complete and timely childhood immunization coverage in Sindh, Pakistan; A secondary analysis of cross-sectional survey data. PloS one. 2018;13(10): e0206766.

68. Mrisho M, Obrist B, Schellenberg JA, Haws RA, Mushi AK, Mshinda H, et al. The use of antenatal and postnatal care: perspectives and experiences of women and health care providers in rural southern Tanzania. BMC Pregnancy Childbirth. 2009;9(1):10.

69. Mutua MK, Kimani-Murage E, Ettarh RR. Childhood vaccination in informal urban settlements in Nairobi, Kenya: who gets vaccinated? BMC Public Health. 2011;11(1):6.

70. Antai D. Rural-urban inequities in childhood immunisation in Nigeria: The role of community contexts. Afr J Primary Health Care Family Med. 2011; 3(1).

71. Buckles KS, Munnich EL. Birth spacing and sibling outcomes. J Hum Resour. 2012;47(3):613-42.

72. Adedokun ST, Uthman OA, Adekanmbi VT, Wiysonge CS. Incomplete childhood immunization in Nigeria: a multilevel analysis of individual and contextual factors. BMC Public Health. 2017;17(1):236.

73. Saari TN. Immunization of preterm and low birth weight infants. Pediatrics. 2003:112(1):193-8

74. Moran EB, Wagner AL, Asiedu-Bekoe F, Abdul-Karim A, Schroeder LF, Boulton ML. Socioeconomic characteristics associated with the introduction of new vaccines and full childhood vaccination in Ghana, 2014. Vaccine. 2020.

75. Calhoun LM, Van Eijk AM, Lindblade KA, Odhiambo FO, Wilson ML, Winterbauer $\mathrm{E}$, et al. Determinants and coverage of vaccination in children in western Kenya from a 2003 cross-sectional survey. Am J Tropical Med Hygiene. 2014;90(2):234-41.

76. Navaneetham K, Dharmalingam A. Utilization of maternal health care services in southern India. Soc Sci Med. 2002;55(10):1849-69.

77. Mbengue MAS, Sarr M, Faye A, Badiane O, Camara FBN, Mboup S, et al. Determinants of complete immunization among senegalese children aged 12-23 months: evidence from the demographic and health survey. BMC Public Health. 2017:17(1):630

78. Chidiebere ODI, Uchenna E, Kenechi O. Maternal sociodemographic factors that influence full child immunisation uptake in Nigeria. South Afr J Child Health. 2014;8(4):138-42.

79. Peters DH, Garg A, Bloom G, Walker DG, Brieger WR, Hafizur RM. Poverty and access to health care in developing countries. Ann N Y Acad Sci. 2008; 1136(1):161-71.

\section{Publisher's Note}

Springer Nature remains neutral with regard to jurisdictional claims in published maps and institutional affiliations.

Ready to submit your research? Choose BMC and benefit from:

- fast, convenient online submission

- thorough peer review by experienced researchers in your field

- rapid publication on acceptance

- support for research data, including large and complex data types

- gold Open Access which fosters wider collaboration and increased citations

- maximum visibility for your research: over $100 \mathrm{M}$ website views per year

At $\mathrm{BMC}$, research is always in progress.

Learn more biomedcentral.com/submissions 